\title{
DEVELOPMENT OF DYNAMIC SIMULATION MODEL FOR BUILDING ENERGY MANAGEMENT SYSTEMS
}

\author{
Kristaps Zadeiks ${ }^{1}$, Armands Senfelds ${ }^{1}$, Ansis Avotins ${ }^{1}$, Marcis Dzenis ${ }^{2}$ \\ ${ }^{1}$ Riga Technical University, Latvia; ${ }^{2}$ Lattelecom, Latvia \\ ansis.avotins@rtu.lv, marcis.dzenis@lattelecom.lv
}

\begin{abstract}
The aim of the research is to develop a new energy management model for building HVAC systems that would enable the use of sensors that would allow data aggregation and analysis. The developed model is based on five resistances, one capacitance (5R1C) energy consumption calculation model described in ISO 13790:2008 standard and used for calculation of the energy use for the space heating for residential and non residential buildings. The 5R1C model is improved by taking into account additional parameters, like building infiltration and the heating system heat capacity, which leads to a new 8R2C model in order to gain more accurate simulation of the building energy performance. First verifications were done by comparing the model performance within "IDA Indoor Climate and Energy" dynamic multi-zone simulation and MatLab simulation software, where simple building (single zone) was tested with different outdoor climate data and different HVAC equipment time schedules. Afterwards, the new 6R1C model was validated by comparing its results to real measurements done in the Riga Technical University, Faculty of Power and Electrical Engineering building, where several heat meters, electricity meters and temperature sensors where installed in order to acquire a detailed information about building energy consumption and indoor climate parameters. The newly developed model enables the possibility to identify an optimal HVAC equipment working parameters to achieve the desired building indoor climate conditions.
\end{abstract}

Keywords: 5R1C, 6R1C, building simulation, EN ISO 13790, IDA ICE.

\section{Introduction}

The international standard [1] defines the energy consumption calculation method that is widely applied in Europe for simple and fast building energy consumption modelling. It has also served as basis for the Latvian national standard covering the energy audit procedure for buildings [2]. Applicability of simplified models in order to evaluate the building compliance with the existing standards has also been evaluated by [3]. Fundamental approach to building energy modelling is based on a simplified 5R1C building energy calculation method developed by several experts in European countries within the CEN standardization committee and PASSYS-II project in 1993. The basic structure of the 5R1C model is shown in Fig.1. The main energy storage ability is related to thermal mass and its capacity to store energy resulting in main thermal capacitance $C$.
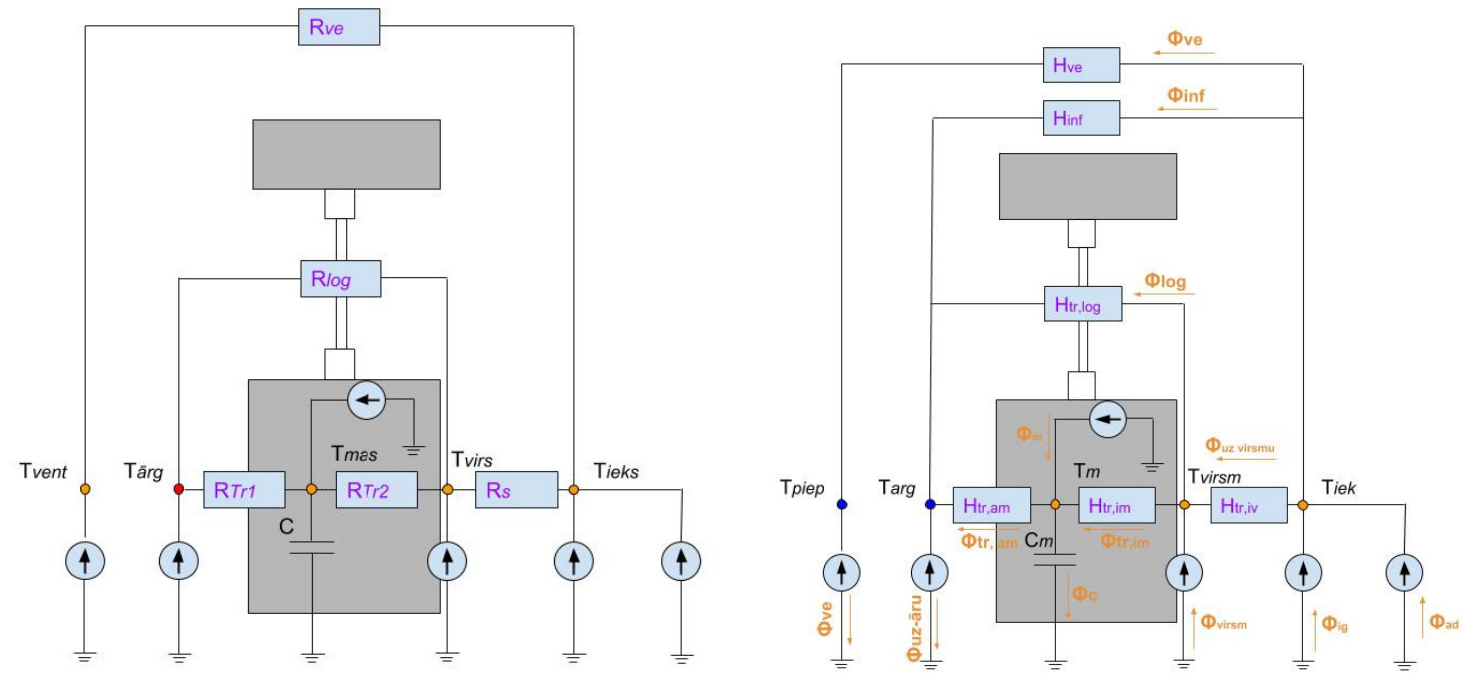

Fig. 1. Lumped 5R1C (left) and 6R1C (right) building thermal model

However, this structure can be modified in order to achieve better results regarding the HVAC system presence in buildings. One of such examples has been discussed by [4] as 6R1C structure. Created RC network structure in [5] shows that very different structures can be created in order to simulate complicated building systems. Proposed model by [6] is based on hourly average 
consumption and can be connected to building utilization data, e.g. number of persons, operation of equipment, lighting. It is based on equivalent RC network as shown in Fig. 1.

The model utilizes temperature differences between the inside air temperature and building surface average temperature values. It enables an option to evaluate indoor comfort and improve accuracy, since energy gain from radiation and convection from the sunlight, lighting, persons and other heat sources has been taken into account. Calculation method is based on simplified heat exchange between the indoor and outdoor environment.

Main reason for modification from 5R1C to 6R1C is that initially components of forced air supply with controlled parameters, e.g. temperature and airflow, are not decoupled from infiltration air exchange with uncontrollable behaviour. Infiltration is independent from ventilation, therefore, it should be calculated by the individual component $H_{\text {inf }}$ along with the ventilation component $H_{v e}$.

The model has five temperature variables: $T_{a r g}$ and $T_{i e k}$ for outdoor and indoor air temperature, respectively, $T_{m}$ for thermal mass internal temperature, $T_{\text {virsm }}$ for indoor surface temperature and $T_{\text {piep }}$ for supply air flow by the HVAC system. Thermal resistances $H_{a m}$ and $H_{i m}$ characterize the wall construction thermal properties from outside and inside with respect to the internal equivalent heat capacitance $C_{m}$. Both components $H_{a m}$ and $H_{i m}$ are calculated from the heat transfer coefficient for opaque elements $H_{t r, o p}$ using the following equations:

$$
H_{a m}=\frac{1}{\left(\frac{1}{H_{o p}}-\frac{1}{H_{i m}}\right)},
$$

where

$$
H_{\text {im }}=h_{m s} \cdot A_{m} .
$$

The heat transfer coefficient $h_{m s}$ has a fixed value of $9.1 \mathrm{~W} \cdot \mathrm{m}^{-2} \cdot \mathrm{K}$ [1]. The heat capacitance $C_{m}$ and the effective mass area $A_{m}$ were calculated by the method described in ISO 13786:2017 [7]. Calculation method was verified against the results presented in [8]. $H_{i v}, H_{\log }$ and $H_{v e}$ are thermal resistances for inside air to surfaces, windows and ventilation, respectively. The $H_{i v}$ is calculated using the following equation:

$$
H_{i v}=h_{i v} \cdot A_{v i r s m},
$$

where $h_{i s}$ is the thermal exchange coefficient with fixed value of $3.45 \mathrm{~W} \cdot \mathrm{m}^{-2} \cdot \mathrm{K}$ [1], and $A_{\text {virm }}$ is all the surface area that is facing the conditioned space.

\section{Simplified building model verification and comparison}

In order to verify the 6R1C model performance along with well accepted energy consumption calculation software tools Matlab Simulink model has been developed according to the 6R1C heat flow model. The following picture (see Fig. 2) represents a simplified rectangular building structure of single level with 100 square meter indoor space as basis for comparative modelling.

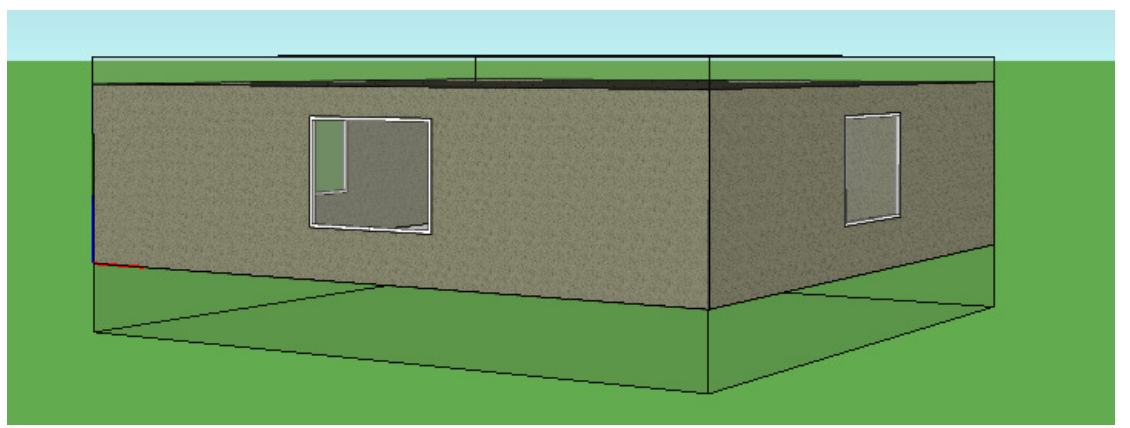

Fig. 2. Simplified single level building for comparative modelling study

Physical thermal properties of building materials considered and respective dimensions have been summarized within Table 1. 
Physical thermal properties of building materials

\begin{tabular}{|c|c|c|c|c|}
\hline $\begin{array}{c}\text { Building structural } \\
\text { elements }\end{array}$ & $\begin{array}{c}\text { Area, } \\
\mathbf{m}^{\mathbf{2}}\end{array}$ & $\begin{array}{c}\text { Heat conduction } \\
\text { coefficient } \mathbf{~} \mathbf{~} \mathbf{W} \cdot(\mathbf{K} \cdot \mathbf{m})^{-2}\end{array}$ & $\begin{array}{c}\text { Heat loss coefficient } \\
\mathbf{U}^{*}, \mathbf{W} \cdot \mathbf{K}^{\mathbf{- 1}}\end{array}$ & $\begin{array}{c}\text { \% of } \\
\text { total }\end{array}$ \\
\hline Walls above ground level & 93.00 & 0.54 & 49.96 & 58.48 \\
\hline Walls below ground level & 0.00 & 0.00 & 0.00 & 0.00 \\
\hline Roof & 100.00 & 0.17 & 17.20 & 20.13 \\
\hline Windows & 9.00 & 1.91 & 17.19 & 20.12 \\
\hline Doors & 2.00 & 0.54 & 1.07 & 1.26 \\
\hline Thermal bridges & - & - & 0.00 & 0.00 \\
\hline Total & 204.00 & 0.42 & 85.42 & 100.00 \\
\hline
\end{tabular}

Additional heating power sources related to operational behaviour within the building according to the time schedule have been summarized in Table 2 .

Table 2

Additional heating power sources related to operational behaviour within the building

\begin{tabular}{|c|c|c|c|c|c|}
\hline Heat source & Units & $\begin{array}{c}\text { Activity level and } \\
\text { clothing }\end{array}$ & $\begin{array}{c}\text { Heat power from } \\
\text { one unit, W }\end{array}$ & $\begin{array}{c}\text { Heat power total, } \\
\text { W }\end{array}$ & $\begin{array}{c}\text { Time } \\
\text { schedule }\end{array}$ \\
\hline Appliances & 1 & - & 200 & 200 & $12: 00-14: 00$ \\
\hline Persons & 6 & 1 Met, 1 Clo & 92 & 550 & $8: 00-19: 00$ \\
\hline Lighting & 5 & - & 60 & 300 & $15: 00-19: 00$ \\
\hline
\end{tabular}

For the evaluation purpose of 6R1C implementation it has been decided to create a test case for two implementations of dynamic building energy consumption models. As reference IDA-ICE (IDA Indoor Climate and Energy) software tool has been selected presenting full modelling workflow for building configuration modelling. Along with dedicated software a new model implementation has been developed based on Matlab Simulink software. Similar comparison has been presented in [9]. After simulation of November month time period with both IDA-ICE software and developed Matlab Simulink model realized 6R1C configuration has led to the following heating energy results of 2200 $\mathrm{kWh}$ for IDA-ICE and $2170 \mathrm{kWh}$ at the Matlab based model. Therefore, the developed 6R1C model presents $1.37 \%$ deviation with respect to the IDA-ICE modelling results. It is possible to obtain more detailed information of components representing total energy consumption and heat flow directions of the building structure as presented in Table 3.

Table 3

Detailed information of components representing total energy consumption and heat flow directions of the building structure

\begin{tabular}{|c|c|c|c|c|c|c|c|c|}
\hline \multirow{2}{*}{ Software } & \multirow{2}{*}{$\begin{array}{c}\text { Wall } \\
\text { constru- } \\
\text { ctions, }\end{array}$} & $\begin{array}{c}\text { Windows } \\
\text { and solar } \\
\text { rWdiation, }\end{array}$ & $\begin{array}{c}\text { Mechan- } \\
\text { racal } \\
\text { ientilat- } \\
\text { vWh }\end{array}$ & $\begin{array}{c}\text { Natural } \\
\text { infiltrat- } \\
\text { ion and } \\
\text { ionh } \\
\text { ventilat- } \\
\text { ion, } \mathbf{k W h}\end{array}$ & $\begin{array}{c}\text { kersons, } \\
\mathbf{k W h}\end{array}$ & $\begin{array}{c}\text { Heat gain from } \\
\text { applian- } \\
\text { ces, } \\
\mathbf{k W h}\end{array}$ & $\begin{array}{c}\text { light- } \\
\text { ing, } \\
\mathbf{k W h}\end{array}$ & $\begin{array}{c}\text { heating } \\
\text { system, } \\
\mathbf{k W h}\end{array}$ \\
\hline $\begin{array}{c}\text { Matlab } \\
\text { 6R1C }\end{array}$ & -910.1 & -68.6 & -529.0 & -890.0 & 181.5 & 12 & 36 & 2170 \\
\hline IDA-ICE & -935.3 & -80.1 & -526.9 & -874.7 & 172 & 12 & 36 & 2200 \\
\hline Difference \% & $2.69 \%$ & $14.31 \%$ & $-0.40 \%$ & $-1.75 \%$ & $-5.52 \%$ & $0.00 \%$ & $0.00 \%$ & $1.37 \%$ \\
\hline
\end{tabular}

It can be observed that almost all of individual heat loss and gain individual components present close results for both IDA-ICE and 6R1C calculation. However, few elements present slight deviations. It can be described by different calculation methods of both software tools, but the total energy consumption to be added by the heating system is close with acceptable accuracy. Largest deviations are present within the window and solar radiation sector. Such value represents the total heat loss through windows subtracted by the heat gain from solar radiation. It can be explained by deviation in the methodology and calculation, since IDA-ICE software distinguish direct solar 
radiation and radiation absorbed by the window structure and released indoors through convection. However, the 6R1C model does not distinguish such components and operates with single value of heat gain resulting in the indoor air temperature. Therefore, it can be stated that both software tools do not reflect ideally the same conditions and some variation is acceptable.

Fig. 3 represents additional heat power variation for the building within one-month time period. It can be observed that both lines represent similar behaviour and the total integrated values correspond. Also this figure represents larger oscillation amplitude of the 6R1C Matlab model compared to the IDA-ICE model. This has direct influence on implemented the heating system PI controller parameters comparing the real room temperature and the set point of $22{ }^{\circ} \mathrm{C}$ as the desired room temperature. Since the total heating energy over one-month period has close results, additional tuning of the PI controller would lead to better correlation of both models during transition periods of shorter time span and even better precision of the developed Matlab model.

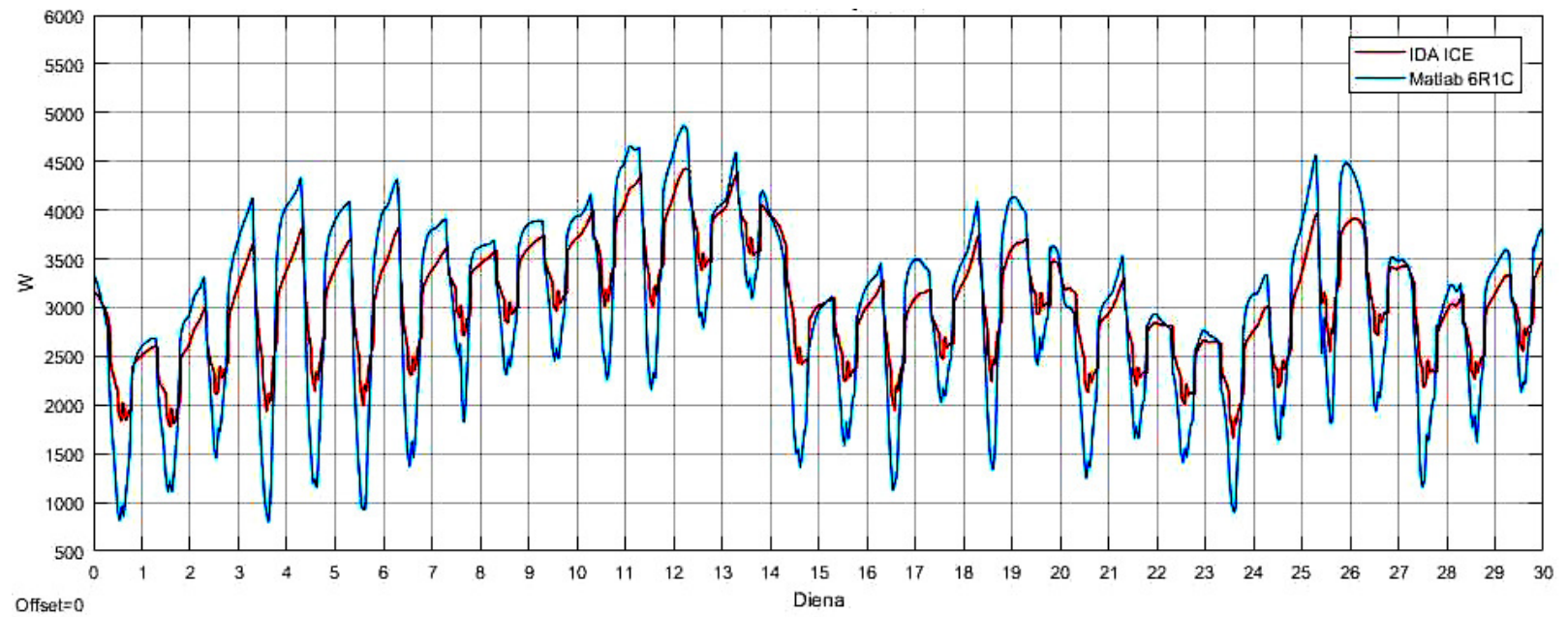

Fig. 3. Heating power variation of both models for same modelling period

\section{Realistic building modelling}

After validating the $6 \mathrm{R} 1 \mathrm{C}$ to a simplified building model and comparing the results with the IDAICE software, the model performance was further tested by comparing its results to real measurements done at the Riga Technical University, Faculty of Power and Electrical Engineering (EEF), where several heat meters, electricity meters and temperature sensors were installed to acquire a detailed information about the building energy consumption and indoor climate parameters. The main parameters of the EEF building's model were estimated using the building's project designs and the values used in the 6R1C model are listed in Table 4.

Values used in the 6R1C model

Table 4

\begin{tabular}{|c|l|c|c|}
\hline Parameter & \multicolumn{1}{|c|}{ Description } & Value & Unit \\
\hline$A_{g r i d}$ & Conditioned floor area & 8135.07 & $\mathrm{~m}^{2}$ \\
\hline$A_{k o p}$ & Area of all surfaces facing the building zone & 36607.82 & $\mathrm{~m}^{2}$ \\
\hline$H_{t r, o p}$ & $\begin{array}{l}\text { Thermal transmission coefficients of opaque building } \\
\text { elements }\end{array}$ & 1403.18 & $\mathrm{~W} \cdot \mathrm{K}^{-1}$ \\
\hline$H_{t r, l o g}$ & $\begin{array}{l}\text { Thermal transmission coefficients of doors, windows, } \\
\text { curtain walls and glazed walls }\end{array}$ & 1665.10 & $\mathrm{~W} \cdot \mathrm{K}^{-1}$ \\
\hline$H_{v e}$ & Ventilation characteristics & 19914.65 & $\mathrm{~W} \cdot \mathrm{K}^{-1}$ \\
\hline$H_{t r, i v}$ & $\begin{array}{l}\text { Coupling conductance between the air node } T_{i e k} \text { and the } \\
\text { surface } \\
\text { node } T_{\text {virsm }}\end{array}$ & 126296.96 & $\mathrm{~W} \cdot \mathrm{K}^{-1}$ \\
\hline$H_{t r, i m}$ & $\begin{array}{l}\text { Coupling conductance between the air node } T_{\text {virs }} \text { and the } \\
\text { surface } \\
\text { node } T_{m} .\end{array}$ & 185072.84 & $\mathrm{~W} \cdot \mathrm{K}^{-1}$ \\
\hline
\end{tabular}


Table 4 (continued)

\begin{tabular}{|c|l|c|c|}
\hline Parameter & \multicolumn{1}{|c|}{ Description } & Value & Unit \\
\hline$H_{t r, a m}$ & $\begin{array}{l}\text { Coupling conductance between the air node Tm and the } \\
\text { surface } \\
\text { node } T_{a r g}\end{array}$ & 1413.90 & $\mathrm{~W} \cdot \mathrm{K}^{-1}$ \\
\hline$C_{m}$ & Internal heat capacity & 1342.27 & $\mathrm{MJ} \cdot \mathrm{K}^{-1}$ \\
\hline$A_{m}$ & Effective mass area & 20337.68 & $\mathrm{~m}^{2}$ \\
\hline
\end{tabular}

In this case building simulation was done by using the real climate data measured by the weather station installed on the EEF building's roof. From the gathered date average hourly values of the outdoor temperature and solar irradiation were calculated. As the weather station only measures the GHI component of the solar irradiation, the method described in [10] was used in order to calculate the DNI and DHI radiation components. The simulation period was chosen from 1.12.2017. till 31.12.2017., and the results were compared with the heat meter readings installed in the building heating substation before the heating circuit heat exchanger. Therefore, the exact consumed energy for the EEF building space heating is known.

It was estimated that around 151 occupants are present in the building during the working hours from 8:00 to 20:00 during weekdays and on Saturday, and that there are no occupants present during Sunday. Schedules for AHU units were taken into account with the average working schedules also being from 8:00 to 20:00 for weekdays and from 10:00 to 14:00 for Saturdays and Sundays with the supply temperature being $20^{\circ} \mathrm{C}$ during the operating hours. In the EEF building the room set point temperature during the nonworking hours is lowered from $22{ }^{\circ} \mathrm{C}$ to $20^{\circ} \mathrm{C}$. This night setback is active during the times, when no occupants are present in the building.

To get more accurate results, the building total measured electricity consumption data were taken into account to precisely estimate the heat gains form the equipment and lighting. Electricity consumption data were not separated in two parts to precisely estimate the gains of the equipment and the lighting, as this was not a part of the aim of this research. For data analysis the simple comparative statistical data analysis is used.

\section{Results and discussion}

During the simulation it was calculated that the total heat energy consumption during December was $32.33 \mathrm{MWh}$ in comparison to the real measured data of $36.24 \mathrm{MWh}$. We can estimate that the model works with $10.68 \%$ precision for the given simulation period. The comparison between the real measurements and the simulated values for the cumulative energy consumption values are given in Fig. 4. From the graph it can be clearly seen that the real measurements of the heat energy consumption are more steady and constant in comparison to the 6R1C model.

This can be explained by the fact that the heat is supplied directly to the room air temperature node $T_{i e k}$, thus allowing the room temperature to change almost instantly, if the supplied heat power is changed. Also the 6R1C model does not take into account that the building heating system has its heat capacity and it is not possible to control the amount of the heat supplied to the room so rapidly. In Fig. 7. we can see the energy sources that affect the room temperature.

These sources are the building heating system and internal gains from lighting, equipment and occupants (see Fig. 5.). As previously stated, in this case the internal gains from light and equipment are combined into one component. Heat gain data from the equipment and the lighting have the most realistic characteristics as the real measured data are used. It can also be seen that the supplied heating power from the heating system has a spike like pattern, which is a result of the fast reacting PI controller that was created in Matlab Simulink environment and regulates the supplied heating power to maintain the required room temperature set point values. This fast reaction speed also affects the simulated room temperature values that can be seen in Fig. 6.

We can see that the room temperature follows the given set point adequately and it can maintain its value despite the internal gains and the changes in the outdoor temperature. Although in the real life the mean air temperature of the whole building does not change so rapidly. We can clearly see that the 
6R1C model can be improved in order to represent more realistic characteristics of the building performance and indoor climate parameters.

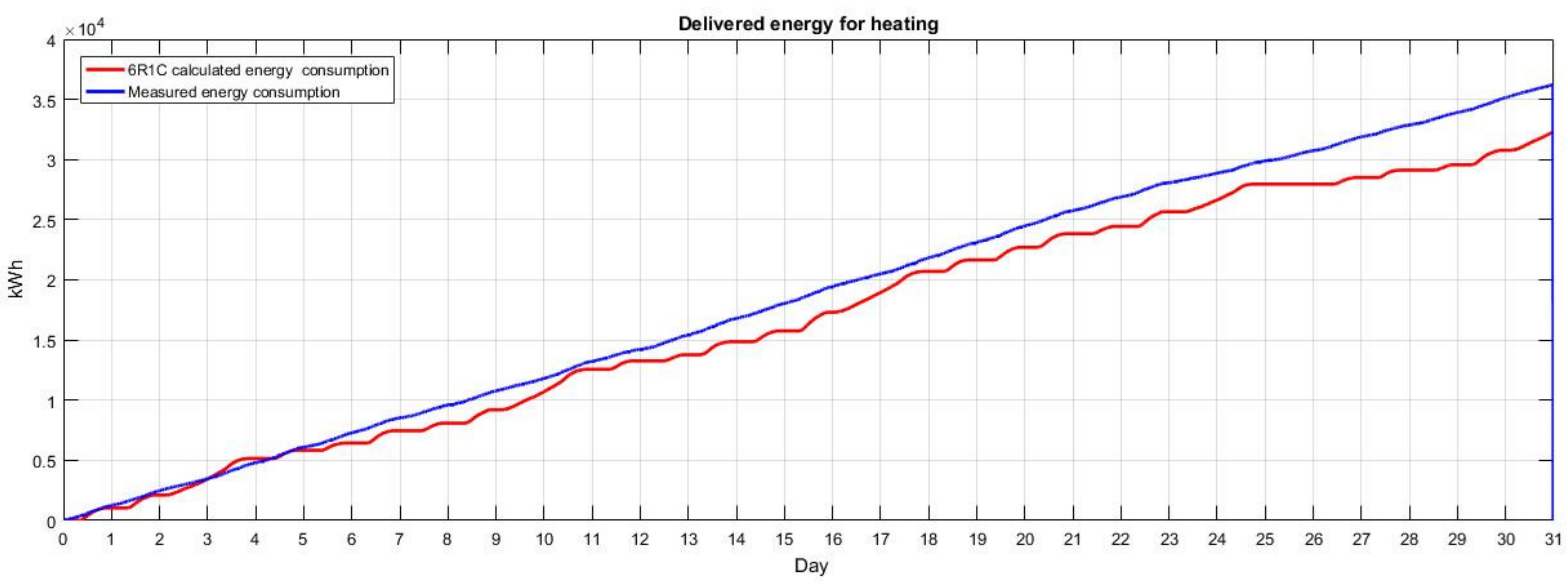

Fig. 4. Comparison of delivered energy for heating needs

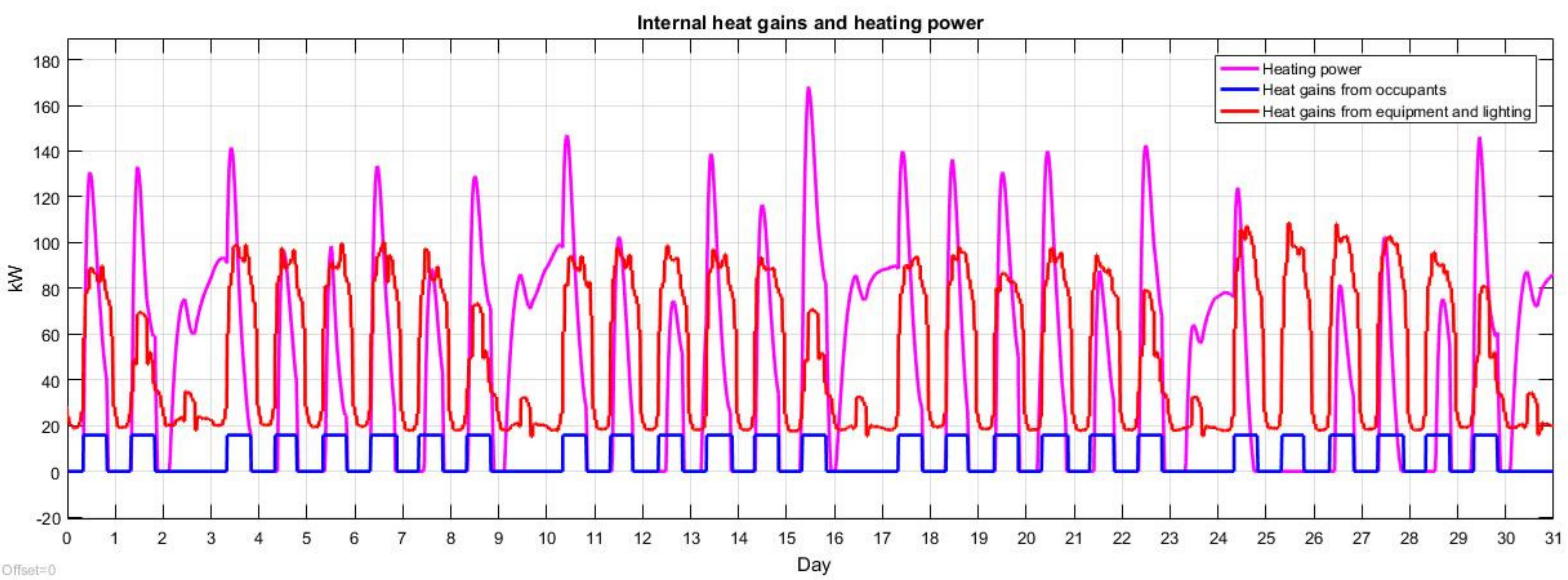

Fig. 5. Internal heat gains and heating power

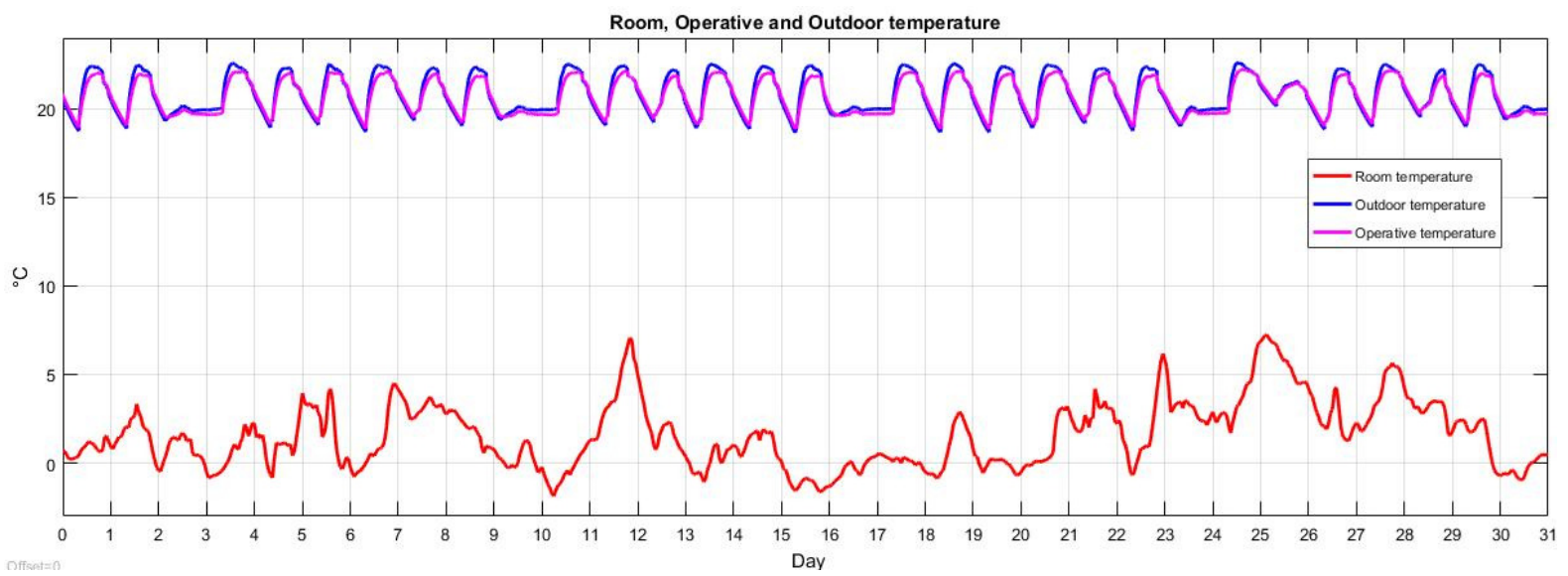

Fig. 6. Room, operative and outdoor temperature

It has been previously proved that the presented 5R1C based model according to EN ISO 13790 can be successfully used to evaluate the annual heating energy demand for the buildings [4]; [6]. Furthermore, this research shows that the model shows adequate results, when simulating shorter time periods. However, from Figures 4-6 we can conclude that the 6R1C model does not reflect the instantaneous mean temperature and the supplied heating power values correctly, as these changes are too rapid in comparison to the real building behaviour. Therefore, further research is needed to improve the model by adding components that would simulate the behaviour of real hydronic heating systems, as it has been tried previously in researches like [10]. In order to improve the model we 
propose the $8 \mathrm{R} 2 \mathrm{C}$ model that adds additional two resistance $\left(H_{t r, a p k}, H_{t r, s m}\right)$ and one capacitance $\left(C_{a p k}\right)$ components between the air temperature node and the point, where the heat is supplied (Fig. 7).

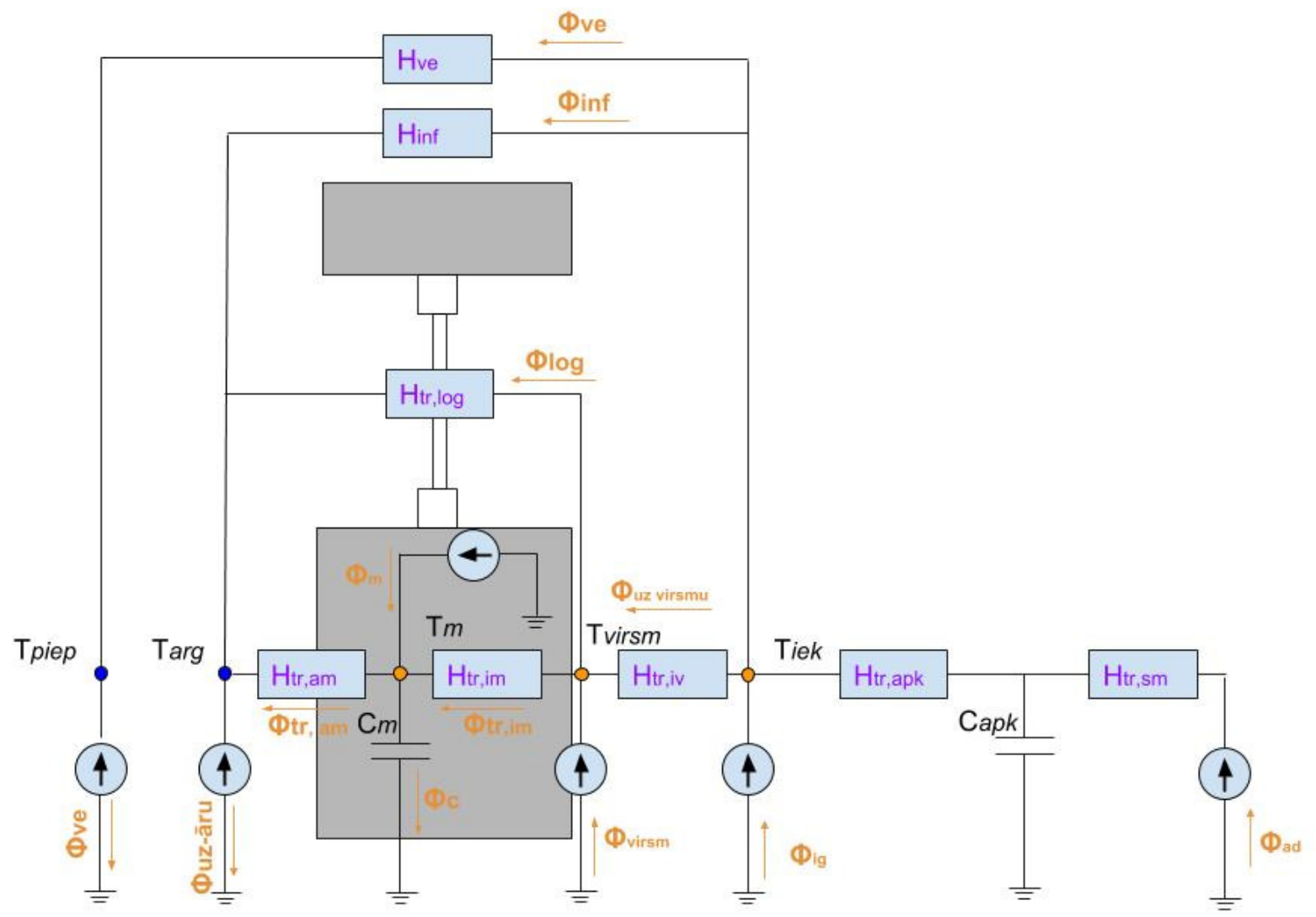

Fig. 7. Modification to 8R2C model

These components should simulate the behaviour of the hydronic heating system and improve the model in a way to more accurately represent the instantaneous values in the shorter time scale. Capacitance $C_{a p k}$ should be calculated as the total heat capacity of the building heating system. Resistance $H_{t r, a p k}$ should represent the heat transfer rate between the radiators and the room temperature and the resistance $H_{t r, s m}$ should represent the heat transfer in the heat exchanger located in the building's heating substation.

\section{Conclusions}

1. 6R1C mathematical model testing in case of a simplified building shows similar results, both in Matlab and IDA-ICE environments, having $1.37 \%$ difference in heat gain from the heating system.

2. Simulation results show that the total heat energy consumption during December is $32.33 \mathrm{MWh}$ in comparison to the real measured data of $36.24 \mathrm{MWh}$, thus the model works with $10.68 \%$ precision.

3. Precision could be improved by introduction of the $8 \mathrm{R} 2 \mathrm{C}$ model, where behaviour of the hydronic heating system (thermal mass) is added.

4. For further research more detailed error analysis should be done and more building types tested.

\section{Acknowledgements}

The research leading to these results has received funding from the research project "Competence Centre of Information and Communication Technologies" of the EU Structural funds, contract No. 1.2.1.1/16/A/007 signed between IT Competence Centre and Central Finance and Contracting Agency, Research No. 1.13. "Development of data collection, analysis and aggregation model for industrial objects and their energy system control". 


\section{References}

[1] ES Standard, EN ISO 13790:2008 "Energy performance of buildings - Calculation of energy use for space heating and cooling", 2008.

[2] LVS, Energoaudits. 2. daḷa: Ëkas, "LVS EN 16247-2:2015", Latvijas valsts standarti, Rīga, 2009.

[3] Viktors Homics, Morten Kirkedal, "Evaluation of simplified models for checking compliance with building regulations: Prediction of thermal comfort in dwellings", Master thesis, Aalborg university, Denmark 2013, 256 p.

[4] Narowski P., Mijakowski M., Panek A., Rucińska J., Sowa J., Integrated 6R1C energy simulation method - principles, verification and application, CLIMA 2010, 11th REHVA World Congress "Sustainable Energy Use in Buildings", 9th- 12th May 2010, Antalya, Turkey, pp. 1-5, ISBN 978-975-6907-14-6.

[5] Dong B., Poh Lam K., "A real-time model predictive control for building heating and cooling systems based on the occupancy behavior pattern detection and local weather forecasting", Building Simulation, February 2014, Volume 7, Issue 1, pp. 89-106

[6] Narowski P., Mijakowski M., Panek A., Rucinska J., Sowa J. "Proposal Of Simplified Calculation 6R1C Method Of Buildings Energy Performance Adopted To Polish Conditions" Proceedings: CE SB10 Prague - Central Europe towards Sustainable Building 'From Theory to Practice', Prague pp. 1-15, 2010.

[7] ES Standard, ISO 13786:2017 “Thermal performance of building components -- Dynamic thermal characteristics -- Calculation methods", 2017

[8] Di Pernaa C., Stazi F., Ursini Casalenab A., D'Oraziob M., "Influence of the internal inertia of the building envelope on summertime comfort in buildings with high internal heat loads", Energy and Buildings 43 (2011), pp.200-206.

[9] Jacob D., Burhenne S., "Simulation models to optimize the energy consumption of buildings", ICEBO 2008 Berlin, Germany, pp.1-5.

[10] Maxwell E. L. "A Quasi-Physical Model for Converting Hourly Global Horizontal to Direct Normal Insolation”, Technical Report No. SERI/TR-215-3087, Solar Energy Research Institute, 1987., $68 \mathrm{p}$.

[11] Gustafsson J., Delsing J., van Deventer J. "Thermodynamic Simulation of a Detached House with District Heating Subcentral”, Systems Conference, 7-10 April 2008, 2nd Annual IEEE, Montreal, Canada, April 7-10, 2008, pp. 1-8. 